\title{
Dermatome variations in patients with transitional vertebrae
}

\author{
Sepp Seyfert
}

\begin{abstract}
Objectives-To test whether the position of lumbosacral dermatomes varies in the presence of transitional vertebrae.

Material and methods-Fifty consecutive male patients were tested for thoracolumbar and lumbosacral transitional vertebrae by radiography and for the position of the dermatome gap between the lumbar dermatomes L1, L2, L3, and the sacral dermatomes $\mathrm{S} 2$ and $\mathrm{S} 3$. The dermatome gap was documented with the use of the cremasteric reflex, the receptive field of which ends sharply at the gap which allows its delineation.

Results-Thirty two of 50 patients had a normal thoracolumbosacral spinal configuration, 10 patients had transitional vertebrae. The patients with a cranial displacement of the thoracolumbar or lumbosacral vertebral transition showed a dermatome gap which lay significantly more ventrally than in the patients with a normal spinal configuration.

Conclusion-The finding supports the notion of a variant position of lumbosacral dermatomes in the presence of transitional vertebrae in males.
\end{abstract}

(F Neurol Neurosurg Psychiatry 1997;63:801-803)

Keywords: transitional vertebrae; dermatome; cremasteric reflex

The normal segmental muscular supply and the normal dermatomes in humans are well known, mostly from the analysis of segmentally manifested diseases such as zoster, naevi, or disc disease. ${ }^{1}$ Their variation is less well documented, although knowledge of variant nervous territories is relevant-for example, for the preoperative localisation of a compressive radicular lesion. One major segmental variation has been reported from a necropsy series. The lumbosacral plexus was found displaced cranially or caudally by $14 \%-58 \%$, meaning more lumbar or more sacral radicular input respectively. $^{2-5}$ The variation suggests the possibility of concomitant variant nervous supply areas in the periphery in such patients. Two of the necropsy series ${ }^{2-3}$ compared the position of the lumbosacral plexus in the presence or absence of transitional vertebrae. Both studies showed a correlation of a cranial plexus position with a cranial displacement of the thoracolumbar or lumbosacral vertebral transition - that is, less than 24 presacral vertebrae or 11 pairs of ribs or rudimentary 12th ribs, and of a caudal plexus position with a caudal displacement of the thoracolumbar or lumbosacral vertebral transition - that is, more than 24 presacral vertebrae or 13 pairs of ribs. The anatomy of the vertebral column may therefore indicate the position of the lumbosacral plexus.

The cremasteric reflex is a further means by which the position of lumbosacral dermatomes can be described. Its receptive field in the dermatomes L1, L2, and L3 ends sharply at the border with the dermatomes S2 and S3. The reflex cannot be elicited with adequate painless stimuli from beyond that dermatome gap. The gap can be safely determined with the reflex and it has the same position as the dermatome borders found in patients with zoster or other segmental diseases. ${ }^{6}$ As the dermatome gap characterises the local segmental sensory supply, its position should also indicate variations of these supply areas. This pilot study describes the position of the lumbosacral dermatome gap as identified with the cremasteric reflex in patients with a normal vertebral column, and in patients with thoracolumbar or lumbosacral transitional vertebrae, to determine whether the position of the respective dermatomes varies under such conditions.

\section{Patients and methods}

Male patients with urolithiasis were selected for the study, because their $x$ ray urogram can be evaluated for transitional vertebrae and because patients without nervous or other interfering lesions were sought. After oral information and consent, 50 consecutive patients in the age range 20-65 years were tested.

The cremasteric reflex was elicited with soft strokes, using a wooden spatula, with an ipsilateral quick lifting of the testicle of $>3 \mathrm{~mm}$ being defined as an adequate reflex response. Tests with a rapid reflex habituation or with a contraction of the tunica dartos were excluded. In every test area along the medial thigh three separate tests were done. The sites where the 
Table 1 Position of the lumbosacral dermatome gap in 32 patients with a normal thoracolumbosacral spine and on the left side of patient 6

\begin{tabular}{|c|c|c|c|c|c|c|}
\hline Patient No & $\begin{array}{l}\text { Right side } \\
\text { proximal } \\
\text { thigh }\end{array}$ & $\begin{array}{l}\text { Middle } \\
\text { thigh }\end{array}$ & $\begin{array}{l}\text { Distal } \\
\text { thigh }\end{array}$ & $\begin{array}{l}\text { Left side } \\
\text { proximal } \\
\text { thigh }\end{array}$ & $\begin{array}{l}\text { Middle } \\
\text { thigh }\end{array}$ & $\begin{array}{l}\text { Distal } \\
\text { thigh }\end{array}$ \\
\hline 2 & 14 & 17 & 17.3 & - & - & - \\
\hline 3 & 23 & 25 & 17.9 & 28.8 & 27.9 & 19.8 \\
\hline 4 & 20.3 & 23.3 & 26.8 & 17.3 & 17.6 & 13.4 \\
\hline 5 & 15.6 & 17.6 & 17.9 & 17.2 & 16.8 & 19.3 \\
\hline 6 left side ${ }^{\star}$ & & & & 20.1 & 17.3 & 4.8 \\
\hline 8 & - & - & - & - & - & - \\
\hline 7 & 13.6 & 13.5 & 0 & 17.7 & 18.3 & 21.4 \\
\hline 9 & 21.4 & 21.4 & 23.2 & 21.3 & 22.9 & 22.8 \\
\hline 10 & 18.5 & 17 & 18.2 & 14.4 & 12.5 & 14 \\
\hline 12 & 13.5 & 15.4 & 17.1 & - & - & - \\
\hline 13 & 17.6 & 22.4 & 19.5 & 24.5 & 24.2 & 23 \\
\hline 15 & 19.2 & 23.4 & 20.7 & 20.7 & 25.5 & 22.7 \\
\hline 16 & 21.7 & 25.8 & 25.6 & 22.9 & 26.1 & 20.5 \\
\hline 17 & - & - & - & 12 & 17 & 18 \\
\hline 24 & 11.6 & 19 & 20.7 & 12.5 & 17 & 23.2 \\
\hline 26 & 19 & 18.5 & 17 & - & - & - \\
\hline 28 & - & - & - & - & - & - \\
\hline 30 & 14.4 & 19.2 & 16 & - & - & - \\
\hline 32 & 22.1 & 23.6 & 25.6 & 7.6 & 20 & 20.9 \\
\hline 33 & 17.7 & 22 & 24.7 & 0 & 13.7 & 14.8 \\
\hline 35 & 17.9 & 17 & 15.7 & 16.8 & 20.4 & 17.5 \\
\hline 36 & 13.5 & 21.9 & 19.2 & 20 & 23.7 & 22.4 \\
\hline 37 & 21.7 & 22.1 & 22.1 & 17.2 & 19.2 & 22.1 \\
\hline 38 & - & - & - & - & - & - \\
\hline 40 & - & - & - & - & - & - \\
\hline 41 & 24.1 & 23.8 & 19.5 & 23.2 & 23.7 & 17.5 \\
\hline 42 & - & - & - & - & - & - \\
\hline 43 & 18.7 & 21.1 & 0 & 17.9 & 20.2 & 0 \\
\hline 44 & 19.5 & 16.3 & 12.9 & 20.5 & 20.4 & 17.2 \\
\hline 45 & 13.3 & 19.6 & 18.3 & 17.9 & 15.7 & 10.8 \\
\hline 46 & 15.6 & 17 & 6 & 13.6 & 16.5 & 12.2 \\
\hline 47 & - & - & - & - & - & - \\
\hline 49 & 13 & 17 & 11.6 & - & - & - \\
\hline
\end{tabular}

* The right side of patient 6 is not included because of hemilumbarisation. The numbers represent the distance of the gap to a reference line between the pubic bone tuberculum and the medical epicondylus of the femur, being expressed as percentage of the circumference of the thigh. $=$ An inadequate cremasteric reflex.

reflex could no longer be elicited varied among the three tests by $<1.6 \mathrm{~cm}$; their mean was defined as indicating the dermatome gap. Repeated reflex testing in five patients showed no statistical difference between the tests, the variances being 5.1 within patients and 13.6 between patients. For a standardised description of the gap position a reference line was drawn from the pubic bone tuberculum to the medial epicondylus of the femur. The distances of the dermatome gap to this line at the proximal, the middle, and the distal quarter points of the line were measured and are given in the tables as percentages of the respective circumference of the thigh.

Urograms of all 50 patients and thorax radiography of 42 of 50 patients were evaluated for transitional vertebrae and corresponding costal variations. The positions of the dermatome gap were statistically tested with the MannWhitney rank sum test.

\section{Results}

The cremasteric reflex was adequate for the delineation of the dermatome gap on 73 of 100 thighs from 42 of 50 patients-that is, in 31 patients on both sides and in 11 patients on one side. The positions of the gap in the 31 patients in whom the cremasteric reflex was adequate on both sides were statistically not different on the left and right sides.

The vertebral column had a normal configuration in 32 of the 42 patients of whom radiography of the thoracic and lumbosacral spine was available. A further patient (6, tables 1 and 2) had a normal vertebral column on the left side and a hemilumbarisation of the first sacral vertebra on the right side. From these 32 patients and the normal left side of patient No 6 , cremasteric reflexes were adequate on 47 thighs in 27 patients. Tables 1 and 3, and the figure give the position of the dermatome gap and its variation.

The radiographs showed a cranial displacement of the thoracolumbar or lumbosacral vertebral transition in seven of 42 patients. ${ }^{2}$ Three patients had 11 pairs of ribs, two of whom had six lumbar vertebrae; three further patients had rudimentary 12th ribs; one of them had a sacralised fifth lumbar vertebra, and one further patient had a sacralised fifth lumbar vertebra. From these seven patients,

Table 2 Position of the lumbosacral dermatome gap in seven patients with a cranial displacement of the thoracolumbar or lumbosacral vertebral transition $(A)$, two patients with a caudal displacement of the thoracolumbar or lumbosacral vertebral transition plus the right side of patient $6(B)$, and eight patients with only a urogram available $(C)$

\begin{tabular}{|c|c|c|c|c|c|c|}
\hline Patient $N o$, spinal configuration & $\begin{array}{l}\text { Right side } \\
\text { proximal thigh }\end{array}$ & Middle thigh & Distal thigh & $\begin{array}{l}\text { Left side } \\
\text { proximal thigh }\end{array}$ & Middle thigh & Distal thigh \\
\hline \multicolumn{7}{|l|}{$\overline{\mathrm{A}}$} \\
\hline \multicolumn{7}{|l|}{14,12 th ribs rudimentary sacralised } \\
\hline 5 th lumbar vertebra & 18.3 & 19.6 & 21.4 & 14.2 & 13.9 & 8.3 \\
\hline 20,12 th ribs rudimentary & 10.8 & 22.4 & 21.7 & 15.9 & 14 & 0 \\
\hline 22 , sacralised 5 th lumbar vertebra & 0 & 18.2 & 20 & 8.2 & 16.4 & 18 \\
\hline 23,11 ribs, 6 lumbar vertebrae & 10.3 & 11.4 & 11.4 & 18.3 & 16.7 & 17 \\
\hline 29,11 ribs & 13.9 & 19.2 & 19.1 & 15.7 & 12.5 & 5.6 \\
\hline 31,12 th ribs rudimentary & - & - & - & - & - & - \\
\hline 39,11 ribs, 6 lumbar vertebrae & 15.1 & 18.8 & 20.2 & 11.9 & 16.8 & 9.3 \\
\hline \multicolumn{7}{|l|}{$\mathrm{B}$} \\
\hline $\begin{array}{l}6 \text {, right side }{ }^{\star} \text {, hemilumbarised } 1 \text { st } \\
\text { sacral vertebra }\end{array}$ & 22 & 26.7 & 22.6 & & & \\
\hline $\begin{array}{l}\text { 11, lumbarised } 1 \text { st sacral vertebra } \\
21 \text {, lumbarised } 1 \text { st sacral vertebra, } \\
\text { costiform processes/1st lumbar }\end{array}$ & - & - & - & 10.9 & 18.9 & 15.9 \\
\hline vertebra & 15.2 & 17 & 17.5 & 12.6 & 18 & 0 \\
\hline \multicolumn{7}{|l|}{$\mathrm{C}$} \\
\hline 1 & 16.8 & 16.7 & 14.5 & 15.8 & 19.3 & 7.8 \\
\hline 18 & 19.6 & 24.7 & 21 & 15 & 19.8 & 18.1 \\
\hline 19 & 12.9 & 14.6 & 7.9 & 17.7 & 15.7 & - \\
\hline 25 & 15 & 19.6 & 18.9 & - & - & - \\
\hline 27 & 18.4 & 22.2 & 21.4 & - & - & - \\
\hline 34 & - & - & - & - & - & - \\
\hline 48 & 17.4 & 23.1 & 21.4 & 12.1 & 16.3 & 17.9 \\
\hline 50,13 pairs of ribs & - & - & - & 15.2 & 17.1 & 0 \\
\hline
\end{tabular}

For measurement details see table 1 and text. 
Table 3 Position of the gap between the dermatomes L1, L2, L3 and S2, S3, as determined by the cremasteric reflex

\begin{tabular}{llll}
\hline Position of dermatome gap & $\begin{array}{l}\text { Normal spinal } \\
\text { configuration }(n=47)\end{array}$ & $\begin{array}{l}\text { Cranial displacement of } \\
\text { vertebral transition } \\
(n=12)\end{array}$ & $\begin{array}{l}\text { p Value } \\
\text { Mann-Whitney rank } \\
\text { sum test }\end{array}$ \\
\hline $\begin{array}{l}\text { On proximal thigh } \\
\text { On middle thigh }\end{array}$ & $17.5(4.8)$ & $12.7(5.1)$ & 0.004 \\
On distal thigh & $19.9(3.7)$ & $16.7(3.2)$ & 0.01 \\
\hline
\end{tabular}

$\mathrm{n}=$ Number of adequate cremasteric reflexes. The numbers (mean (SD)) represent the distances of the dermatome gap to a reference line between the pubic bone tuberculum and the medial epicondylus of the femur, being expressed as perentage of the circumference of the thigh. The dermatome gap lies more ventrally in patients with a cranially displaced thoracolumbar or lumbosacral vertebral transition, compared with patients with a normal spinal configuration.

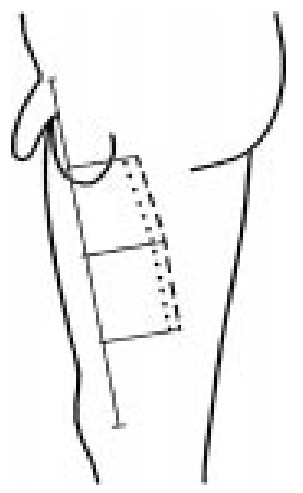

The position of the gap between the dermatomes $L 1, L 2, L 3$, and S2, and $S 3$, as documented by the cremasteric reflex in patients with a normal spinal configuration (dashed line) and, lying more ventrally, in patient with a cranially displaced thoracolumbar or lumbosacral vartebral transition (dotted line). cremasteric reflexes were adequate on 12 thighs of six patients. The dermatome gap lay significantly more ventrally at the proximal and at the middle quarter points of the medial thigh, compared with the patients with a normal spinal configuration (tables 2 and 3 and the figure).

The radiographs showed a caudal displacement of the thoracolumbar or lumbosacral vertebral transition in two of 42 patients. ${ }^{2} 7$ Both patients had a lumbarised first sacral vertebra, one of them also had costiform processes on the first lumbar vertebra. The hemilumbarisation side of patient No 6 was added to this subgroup. The cremasteric reflex was adequate on four thighs with the dermatome gaps showing a variation as in the other subgroups (table 2). Because of the small number a statistical comparison with the other patients is not reasonable.

In eight of 50 patients only a urogram but no thoracic radiograph was available. From seven of these patients with normal lumbar vertebrae, cremasteric reflexes were adequate on 10 thighs of six patients (table 2). The position of the dermatome gap was not different from the patients with a normal spinal configuration.

\section{Discussion}

A careful use of the cremasteric reflex allows reliable documentation of the border of its receptive field at the mediodorsal aspect of the thigh, which corresponds to the gap between the dermatomes $\mathrm{L} 1, \mathrm{~L} 2$, and L3 on its medial side and S2 and S3 on its dorsal side. With this technique, the present study showed some variation of the dermatome gap between patients, with an overlap between the patients with a normal configuration of the spine and the patients with transitional vertebrae. The finding is not surprising, as a similar variation of the lumbosacral plexus has been reported in necropsy series..$^{2-4}$

The lumbosacral dermatome gap was found to lie more ventrally in patients with a cranial displacement of the thoracolumbar or lumbosacral vertebral transition than in patients with a normal spinal configuration. As the gap describes the position of the local lumbar and sacral dermatomes, the finding indicates a variant position of the segmental sensory supply of the skin in male patients with this variant vertebral transition. The dermatome variation may, of course, be the continuation of a variant plexus position. The patients with a caudally displaced thoracolumbar or lumbosacral transition of the spine were too few in the present series for a statistical evaluation. It may be mentioned that the patient with hemilumbarisation as a sign of a caudal vertebral transition showed a farther dorsal position of the dermatome gap on this side, compared with the normal configuration on the other spinal side (patient 6, tables 1 and 2).

The anatomy of the lumbosacral plexus, of its radicular input, and of the peripheral supply areas of its branches cannot be visualised in vivo at present. The documentation of the lumbosacral dermatome gap by means of the cremasteric reflex in male subjects, however, indicates the position of lumbosacral dermatomes in vivo, which in turn gives a hint as to the position of the lumbosacral plexus and its radicular input. A description of the whole segmental sensory and motor supply areas in patients with transitional vertebrae - for example, by the use of segmentally manifested diseases - is desirable as an extension of this pilot study.

A further interesting result of the study was the 11 patients found with transitional vertebrae among the 50 with urolithiasis, which is significantly higher than the rates which have been reported in radiography series on patients with lumbosacral pain. ${ }^{8} \mathrm{~A}$ similar finding in patients with urolithiasis has been reported. ${ }^{10}$

The support of Professor Dr K Miller and his colleagues of the Urologic Clinic of the UKBF and of Dr H-C Koch of the Radiologic Clinic of the UKBF is gratefully acknowledged.

1 Schliack H. Klinische Untersuchungen zur Segmentinnervation der Haut. Dtsch Med Wochenschr 1960;85:2144-52.

2 Bardeen CR, Elting A. A statistical study of the variations in the formation and position of the lumbo-sacral plexus in the formation and position of the lumbo-sac
man. Anat Anz 1901;19:124-135, 209-38.

man. Anat Anz 1901;19:124-135, 209-38.
3 Eisler P. Der Plexus lumbosacralis des Menschen. Halle: M Eisler P. Der Plex
Niemeyer, 1892.

4 Severeanu G. Du plexus lombaire. Bibliographie Anatomique 1904;13:299-313.

5 Webber RH. Some variations in the lumbar plexus of nerves in man. Acta Anat 1961;44:336-45.

6 Schliack H. Segmentdiagnostik unter physiologischen Bedingungen mit Hilfe des Cremasterreflexes. Nervenarzt 1958;29:411-4.

7 Bardeen CR. Costo-vertebral variation in man. Anat Anz 1900;18:377-82.

8 Blumensaat C, Clasing C. Anatomie und Klinik der lumbosakralen Ubergangswirbel. Ergebn Chir Orthop 1932;25:159.

9 Hahn PY, Strobel JJ, Hahn FJ. Verification of lumbosacral segments on MR images: identification of transitional vertebrae. Radiol 1992;182:580-1.

10 Tini PG, Wieser C, Zinn WM. The transitional vertebra of the lumbosacral spine. Rheumatol Rehabil 1977;16:180-5. 